\title{
Long-term Managemẹnt of High-level Radioactive Waste
}

A difficult task facing authorities who have the responsibility of arranging the permanent disposal of high-level radioactive waste, is proving that the waste can be safely contained for the very long period during which it will pose a risk to the public. In some countries there have been demands that the long-term safety of disposal systems should be 'demonstrated' as a pre-condition for the further development of nuclear power.

Confronted with this issue, OECD countries in the Nuclear Energy Agency (NEA) supported a proposal to clarify the meaning of the term 'demonstration', and to describe the practical ways to satisfy the demands for proof. The NEA Radioactive Waste Management Committee has recently responded by defining the concept of 'demonstration' and explaining the background against which the issues of permanent disposal should be considered. Copies of a new statement, Longterm Management of High-level Radioactive Waste-the Meaning of a Demonstration, are available free of charge from the Radiation Protection and Waste Management Division, OECD Nuclear Energy Agency, 38 Boulevard Suchet, 75016 Paris, France.

In summary, the 'demonstration' of deep underground disposal of high-level radioactive waste involves two steps:

- One is direct, to prove that the system can be built, operated, and closed, safely and at acceptable costs, using available mining and engineering experience; this may mean designing and building one or more experimental facilities.

- The other is indirect, to make a convincing evaluation of the system's performance and long-term safety on the basis of predictive analyses, confirmed by a body of varied technical and scientific data, much of it deriving from experimental work.

As far as short-term waste management operations are concerned, repository construction and operation can be directly 'demonstrated' on the basis of the experience gained from representative test facilities. Extension to the industrial scale also seems reasonable, and in some cases has already been accomplished.

On the other hand, the indirect 'demonstration' of the long-term safety and reliability of disposal concepts is not as simple or straightforward. Assessment calls for highly sophisticated scientific techniques, and the results will often leave room for varying interpretation and judgement, due to the uncertainties of far-future situations and the introduction of probabilistic scenarios. However, significant progress has been made in this area in the last few years, and confidence in our ability to predict the performance of waste management systems will increase further, as supporting evidence is collected from current research and development activities and as our predictive techniques improve.

Current studies suggest that an indirect 'demonstration' has the potential to provide the assurance required; but as usual in such situations, national authorities will ultimately have to satisfy themselves that the nature and extent of the evidence show a sufficient understanding of the problems involved, and that the proposed solutions can meet long-term safety objectives.

OECD Information SERVICE

Organization for Economic Cooperation and Development

2 Rue André-Pascal

75775 Paris Cedex 16

France.

\section{Conservation and the Otmoor Ruse}

Friends of the Earth (FOE) in Oxfordshire have been campaigning against plans to extend the M40 motorway ever since these plans were published in 1979. The present M40 runs westwards from London, ending at Wheatley, 5 miles $(8 \mathrm{~km})$ to the east of Oxford. The planned extension would be 46 miles (nearly $74 \mathrm{~km}$ ) long, taking the 6-lanes' highway north to Birmingham. Costing over $£ 250$ millions, the M40 is described by the UK Department of Transport as 'the last motorway'.

FOE's objections are based on the inequalities of Britain's transport policy, which emphasizes private transport to the detriment of public transport. This, FOE believes, discriminates against the poor, the handicapped, and the old, as well as being environmentally and economically short-sighted.

Part of the new motorway would dissect Bernwood Forest, one of Britain's foremost butterfly habitats, and cross Otmoor, an historic semi-wetland lying 6 miles (nearly $10 \mathrm{~km}$ ) north of Oxford. Otmoor's patchwork of tiny fields provided the inspiration for 'Lewis Carroll's' chessboard scene in Through the Looking Glass. These fields form a mixed habitat for a variety of birds, insects, and mammals, and part of the moor is designated as a Site of Special Scientific Interest.

FOE have used Otmoor and Bernwood as the focal points of their campaign, and have won international support through a rather novel attempt to save them. Because they view the British Public Inquiry system as being little more than cosmetic democracy, FOE boycotted the M40 inquiry and with the aid of a local farmer are pursuing a case through the European Court of Human Rights in an attempt to change the inquiry system.

Realizing that this is a very slow process, FOE launched a new campaign. Under present UK law, a Minister wishing to enforce compulsory purchase of land for a new motorway must serve notice on all affected landowners. FOE purchased a 2 -acres $(0.81 \mathrm{ha})$ field on Otmoor, which is in the path of the motorway, and have resold it in tiny plots to 3,000 people all over the world. This will force the Department of Transport to search out all these landowners before they can proceed with the M40 extension as planned.

But FOE are under no illusions about the power of the UK Government, and realize that laws can be changed to side-step their campaign. However, they do hope that their scheme has demonstrated how important Bernwood and Otmoor are as part of the world's natural heritage, and that the UK Government will at least change the route of the motorway to avoid the two wildlife sites.

W.J. WesTon, Coordinator
Wheatley Friends of the Earth
58 Mickle Way
Oxford
England, UK.

